\section{Needs in siblings of individuals with Down Syndrome and levels of coping Cali, Colombia}

\author{
Lina Fernanda Martínez Cadavid ${ }^{1}$, Diana Marcela Gutiérrez \\ Acosta $^{2}$ and Luis Alexander Lovera Montilla ${ }^{3 *}$ \\ ${ }^{1}$ Specialist in Medical Audit, IPS SURA Lead Nurse, Cali, Colombia \\ 2Master's Student in Health Administration, IPS SURA Lead Nurse, Cali, Colombia \\ ${ }^{3}$ Professor, School of Nursing, Universidad del Valle, Cali, Colombia
}

\section{Abstract}

Objective: To determine the needs and level of coping in siblings of people with Down Syndrome.

Methods: Descriptive, cross-sectional study, carried out in 2016. Sample consisted of 30 siblings of people with Down Syndrome between 6 and 60 years old. Using non-probability convenience sampling. Two instruments were used to collect the information: a) a validated sociodemographic and needs survey of the siblings, designed by the authors, and b). Callista Roy adaptation and coping survey validated.

Results: $60 \%$ of the siblings report not having felt judged by other people when presenting their brother/sister with Down syndrome. $73.3 \%$ of the siblings did not receive information about Down Syndrome from a nursing professional, the need to strengthen the nursing care provided to the siblings of people with disabilities in this regard is evident. $53.3 \%$ of these present a medium level of coping with respect to the condition of having a brother with Down syndrome.

Conclusion: Identified needs were: time needs, affective needs, family needs, social needs, economic and access to information needs. Highlighting these needs allows the nursing professional to identify and consider the siblings of people with Down Syndrome have different needs than the rest of the family nucleus. Where interventions aimed at reducing the harmful effects and enhancing those characteristics of gain related with having a brother with Down Syndrome.

\section{More Information}

*Address for Correspondence: Luis Alexander Lovera Montilla, Nurse, Professor, School of Nursing, Universidad del Valle, Cali, Colombia, Email:

luis.alexander.lovera@correounivalle.edu.co

Submitted: October 08, 2021

Approved: October 29, 2021

Published: November 01, 2021

How to cite this article: Cadavid LFM, Acosta DMG, Montilla LAL. Needs in siblings of individuals with Down Syndrome and levels of coping Cali, Colombia. J Adv Pediatr Child Health. 2021; 4: 101-108.

DOI: 10.29328/journal.japch.1001041

ORCiD: orcid.org/0000-0002-8557-4278

Copyright: (c) 2021 Cadavid LFM, et al. This is an open access article distributed under the Creative Commons Attribution License, which permits unrestricted use, distribution, and reproduction in any medium, provided the original work is properly cited.

Keywords: Siblings; Down syndrome; Nursing; Coping

(A) Check for updates

O OPEn Access

\section{Introduction}

Birth defects affect 1 in every 33 infants and cause 3.2 million disabilities per year. It's estimated that every 270,000 newborns die during the first 28 days of life due to congenital anomalies [1]. One of the most common birth defects is Down Syndrome (DS). It occurs in about 1 in every 800 babies $[2,3]$. In 2015 , an estimated 417,000 people were living with Down Syndrome in Europe [4].

In the last census carried out in Colombia in 2005, a rate of 1.72 per 1000 LB (live births) with DS was evidenced. In conformity with this information Colombia occupies the fifth place in Latin America in terms of prevalence of this condition [5].

The (DS) is a genetic alteration produced by the presence of an extra copy of chromosome 21. It represents the most frequent genetic cause of intellectual disability and congenital malformations; this extra genetic material makes people who possess it have their own characteristics of the syndrome. The characteristic features of DS are flattened facial features, decreased Moro reflex, hypotonia, joint hyperlaxity, excess skin on the neck, inclination of the palpebral fissures, pelvic dysplasia, pinna's shape abnormalities and dysplasia of the middle phalanx of the little finger and, finally, simian crease in the palm of the hand [6]. People with DS have clear differences between them, which are determined by genetics, environment of each individual and the degree of disability, which generates a great variety in their mental capacity, behavior and physical development [7-9].

Families of people with DS belong to different ethnic, 
religious and socioeconomic groups. Each family has its own needs when it comes to strengthening the development of the person with DS different spheres, at the same time, each family member develops unique needs regarding the changes at family and personal level associated with having a link with a person with DS. Some families experience stress, but this depends on the strength and resilience presented by the family [10]. Thus, the identification of the needs of families and their members constitutes an important and complex process $[11,12]$.

Some studies indicate that a person with DS influence on their siblings has negative aspects. It has been shown there may be distress, questions to be resolved, emotional overload, among others. In the same way, positive results have been presented in terms of personal enrichment and happiness $([13,14]$. At present it is the parents, for the most part, who provide the daily care until they themselves are elderly; being necessary to have alternative systems. This is where the role played by the siblings of the siblings comes into consideration and the decision they make about whether or not to become involved in providing services to their sibling with disabilities will be influenced by many different factors [15].

Along these lines, it is important both parents and health professionals to be aware of and pay attention to the specific needs of having a brother or sister with some type of disability may entail. Because if these needs aren't identified and a prompt response is not given, the possibility these individuals can develop adequate coping strategies will be lost, regarding all the challenges that having a sister or brother with DS brings. For this reason, this research posed the following question: What are the needs in siblings of people with Down syndrome and the level of coping they use to adapt to the situations that arise?

\section{Methods}

A descriptive cross-sectional design was carried out in the year 2016. This study was conducted on siblings of people with Down Syndrome from the city of Cali, Colombia. A non-probabilistic convenience sampling of 30 siblings was used. They were selected from a sports club where people with DS attend. A presentation of the project was made to the families of people with DS and later to the siblings who wanted to participate in the study. Subsequently, with the endorsement of the institutional ethical review committee of the Universidad del Valle, with the approval certificate 016-16 and internal code 092-016, the study was started after signing the informed consent. The inclusion criteria were: siblings of people with DS who were between the ages of 6 to 60 years of age, regardless of gender, birth order, ethnicity, whether or not they currently live in the family group of the person with DS. Participants who agreed to be part of the study, but who withdrew without applying the data collection instruments were excluded. Within the study variables: the independent variable was the needs of the siblings of people with DS and the dependent variable was their level of coping to adapt to the situations that converge with having a sibling with this disability.

Two instruments were used to collect the information: a) survey of sociodemographic and needs of the siblings of people with Down syndrome, which was adjusted twice, and b) adaptation and coping survey by Callista Roy, (version modified of coping and adaptation process measurement scale EsCAPS in Spanish -original version of Callista Roy) which, we had authorization for its use, by the postgraduate management and the research coordination of the faculty of nursing and rehabilitation at Universidad de la Sabana (Table 1). Table with the items of the two instruments.

For the statistical analysis, Office Excel 2016 program was used for the survey tabulation, taking into account that it was rectified and reviewed by 2 peers when has been inserted the information. The weightings of the responses were according to the scale established in the instrument. Later the data were exported to the statistical package SPSS, version 20. For the analysis of the sociodemographic characterization, a univariate analysis was performed considering the category of the variable. For the open questions, a univariate analysis was carried out. The results were presented in tables and figures in Excel 2016.

\section{Results}

The results will be presented as follows:

a). Sociodemographic characteristics, b). Results of the needs in siblings of people with Down Syndrome and, c). Results of level of coping.

a) Sociodemographic characteristics (Table 2).

b) Needs in siblings of people with Down Syndrome

It was found all study participants defined their relationship with the sibling with DS as satisfactory. Since, it is based on love, respect, and mutual support. $70 \%$ of the participants dedicate part of their time to caring for their brother/ sister. On the other hand, it was asked about the qualities that have been strengthened or diminished by having a brother with DS; about $65 \%$ answered that perseverance, sensitivity, affection, patience and responsibility were the qualities that were most strengthened. In contrast, the negative qualities that most reported are guilt and fear with $20 \%$. It should be mentioned that $100 \%$ of the participants expressed feeling satisfied with the relationship they have with their close friends, and having a sibling with DS has had no influence on their relationship with their peers. However, about half of the siblings who participated in the study (15 participants) stated that they have felt singled out or judged by strangers, for having a sibling with DS. On the other hand, the siblings 
Table 1: Items of the two instruments information collection

Roy Coating and Adaptation Process Measurement Scale, Spanish Version (EsCAPS). Shortened version - Items

When I have a problem or difficult situation, I can follow several directions at the same time

When I have an unexpected problem I find new solutions to solve it

When I have a problem or difficult situation, I accept the problem as it is or as it appears

When I am worried about a problem or difficult situation I have difficulty completing activities, tasks and projects

When I have a problem or difficult situation, I can only think about what worries me about it

I feel good when I think I handle problems to the best of my ability.

When I have a problem or difficult situation, I take the time to understand the situation and its possible solutions

I feel like I can't handle difficult problems or situations

I act slowly when I have a problem or difficult situation

When I have a problem or difficult situation, I try to orient my feelings and emotions to focus them in a fruitful way

When I have a problem or difficult situation, I feel attentive and active during the day When I have a problem or difficult situation, I try not to influence my feelings to see what happens

When I have a problem or difficult situation, I am aware of anything related to the situation

I tend to overreact when I have a problem or difficult situation

When I have a problem or difficult situation, I tend to get blocked and confused at least for a while

When I have a problem or difficult situation, I feel that it is difficult to talk about the problem I do well handling complicated problems

When I have a problem or difficult situation, seek all possible means to face the situation In order to get out of a difficult problem or situation I can make drastic changes in my life My ability to act improves when I am in stressful situations

I can relate problems or difficult situations to my past experiences and to my future plans I tend to feel guilty for any difficulties I have.

I think my past experiences are not helpful in solving difficult situations or problems I use the solutions that have worked for others to solve my difficult situations or problems I see difficult situations or problems as an opportunity or a challenge

When I have a problem or difficult situation, I propose different solutions to solve the situation even if they seem difficult to reach

When I have a problem or difficult situation, I experience changes in the way my body works When I have a problem or difficult situation, I quickly take charge and handle difficulties as they arise.

When I have a problem or difficult situation, I try to clarify any type of doubt related to the situation before acting

When I have a problem or difficult situation, I quickly adopt new skills to solve it

When I have a problem or difficult situation, I give up easily

When I have a problem or difficult situation, I develop a plan that has a series of actions or steps to deal with the situation.

When I have a problem or difficult situation, I have high expectations about how the situation will be resolved
Sociodemographic Survey and Identification of Needs of Siblings of People with Down Syndrome

Gender, age, education level, socioeconomic

$$
\text { Family }
$$

Who are you currently living with?

Educational level of the father, mother

What is the occupation of your parents?

What is the occupation of your parents?

What is the position you occupy with respect to your brother (a) with Down Syndrome?

Needs of the Brothers

Did you receive preparation or explanation from your parents regarding the arrival or condition of your sibling with Down Syndrome?

How are your relationships with your family?

Do you feel that you are part of the decisions that are made at home?

Are you satisfied with the responsibility and role you play in your family?

How is your relationship with your brother or sister with Down syndrome?

How has the time your family spends caring for you made you feel?

Does having a sibling with Down syndrome currently limit you to carry out your daily activities?

Have you had to miss or drop out of school, college, or work to help your sibling with Down syndrome?

How does having a sibling with Down syndrome make you feel?

Do you feel loved by your family?

Have you felt singled out or judged for having a sibling with Down syndrome?

Do you consider that having a sibling with Down syndrome is a cause or did it because you increased stress?

Table 2: Sociodemographic Characterization.

\begin{tabular}{|c|c|c|c|c|c|c|c|c|c|}
\hline & \multicolumn{2}{|c|}{ Age (Years) } & \multirow{2}{*}{$\begin{array}{c}\text { Sex } \\
\text { Female }\end{array}$} & \multirow{2}{*}{$\begin{array}{c}\begin{array}{c}\text { Socio-Economic } \\
\text { Status }\end{array} \\
3 \text { (Middle) }\end{array}$} & \multirow{2}{*}{$\begin{array}{l}\text { Educational Level } \\
\text { Complete High School } \\
\text { Complete Undergraduate } \\
\text { Degree }\end{array}$} & \multicolumn{2}{|r|}{$\begin{array}{l}\text { Civil Status } \\
\text { Parents }\end{array}$} & \multicolumn{2}{|c|}{$\begin{array}{l}\text { Occupation } \\
\text { Parents }\end{array}$} \\
\hline & $6-12$ & $13-60$ & & & & Married & Cohabitation Relationship & Mother: Housewife & Father: Merchant \\
\hline $\mathrm{N}$ & 4 & 26 & 19 & 16 & 6 & 11 & 6 & 11 & 11 \\
\hline$\%$ & 13,3 & 60 & 63,3 & 53,3 & 20 & 36,6 & 20 & 36,6 & 36,6 \\
\hline
\end{tabular}


reported that the only information they received about their brother was about the causes and health complications of DS. In relation to the activities carried out with the sibling with DS, personal hygiene and eating are the most frequent (Graph 1). 50\% of siblings report that they have felt displaced and unattended at some point by their parents. $90 \%$ of the siblings were proud to introduce their sibling to their friends.

c) Adaptation and coping of the siblings of people with Down Syndrome (Graphs 2 and 3).

In general, the average global score of the capacity of coping and adaptation process of the siblings of people with DS was $53.3 \%$ medium, $43.3 \%$ low and 3.3\% high.

Regarding the capacity of the coping and adaptation process due to aspects such as the position of fraternity, abandonment

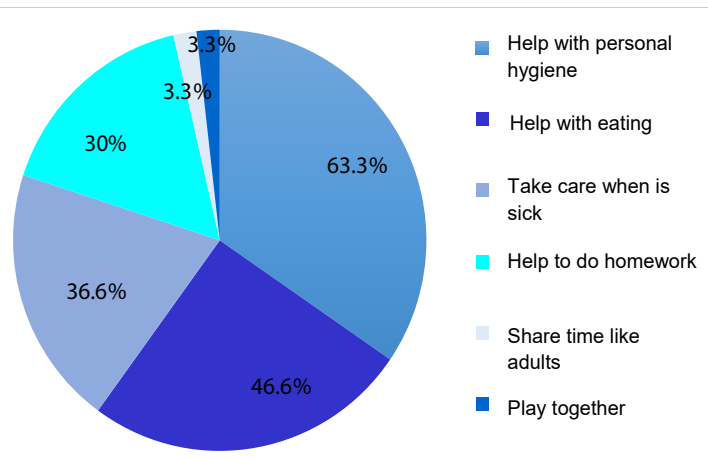

Graph 1: Activities carried out by the siblings.

Afrontamiento de los hermanos de personas con SD

entre los 6 años a 18 años de edad

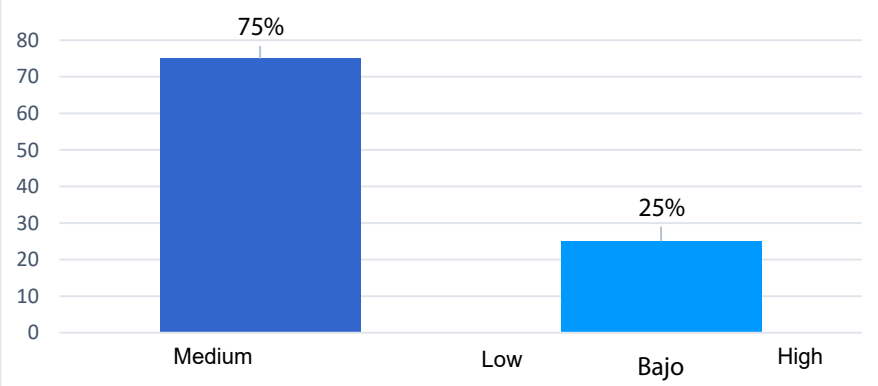

Graph 2: Coping of the siblings of people with DS.

Afrontamiento de los hermanos de personas con SD entre los 18 años a 60 años de edad.

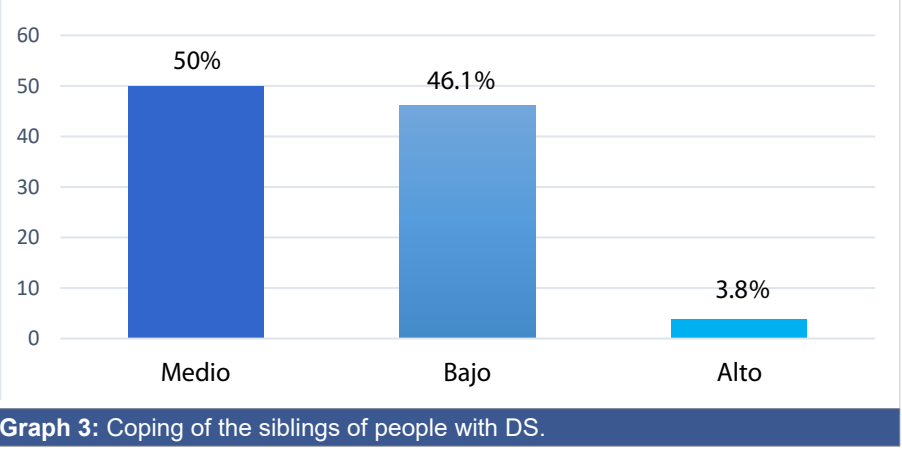

of activities to care for their brother, decision-making at home, they were found in the siblings of people with DS: In the group of 13 at 60 years of age, it is evidenced that the majority of the older siblings did not feel their parents gave more importance to their brother with DS, on the contrary, the younger siblings from 6 to 12 years old had this discrepancy, in this group the ability to cope and adapt was $85 \%$ at the high level. On the other hand, only one participant had to abandon his activities to take care of his brother. In relation to decisions made at home, in general, the capacity of the coping and adaptation process was under $5 \%$. Most of the individuals surveyed, both in the 6 to 12-year-old group and the 13 to 60 -year-old group, reported feeling part of the decisions made at home and all of the participants reported feeling loved by their family.

\section{Discussion}

The siblings of people with DS are part of one of the subsystems of the family and although these families have been studied for many years, there are still large gaps in relation to the different members of the family [16], especially in siblings, who have been considered a group that experiences various feelings and particularities depending on various factors such as: age, fraternity position, socioeconomic level and support referred by the same family nucleus, among others. For this reason, it is important to recognize that these factors influence the needs in siblings of people with DS and the level of coping they use to adapt to the situation. In this sense, this discussion will be guided around: needs and level of coping in siblings of people with DS.

\section{Needs in siblings of people with DS}

Regarding time needs, several studies have shown that the changes that occur in the tasks and activities of people who have a sibling with cognitive deficit and DS are one of the greatest concerns, given the responsibility they assume in the new role as a sibling, which they suppose will have negative effects [17-19]. On the contrary, in the present investigation, it was observed regarding this need, the siblings do not have limitations to carry out their activities and although some negative effects appear for them, this doesn't represent an impediment in their role as siblings, this is more evident in older siblings. These findings can be supported by the study carried out by Lizasoain, where they interviewed older siblings of children with disabilities, where many of them reported that they adapted positively and did not present inconveniences regarding time management or changes in daily plans or activities [13].

Regarding older sisters, they feel more pressure and responsibility, possibly because they are more exposed by their parents to greater domestic responsibility. According to Núñez, cited by the Federación España Down, it indicates that older siblings, especially in large families, feel that attention is focused solely on their brother in situation of disability, where they expressed through interviews they feel resentment for 
the loss of parental attention, due to unequal treatment between siblings and fear of having to reject certain plans in the future because of the sibling with intellectual disabilities [20]. In the present investigation, the findings show that half of the participants who were older expressed that their parents give equal importance to them compared to their siblings with DS. This could possibly be explained because older siblings understand the situation more easily due to the characteristics of their thinking, related to the ability to reflect and analyze the condition of their sibling with DS. In the same way, these facts can also be explained, according to Skotko and Levine, because older siblings tend to mitigate concerns thanks to preparation they had from their parents, their marital satisfaction, having a united family or a relationship between siblings without confrontation [21].

Regarding younger siblings, it was found in the present investigation that they consider that their parents give more importance to their siblings with DS. This can also be explained due to the characteristics of their thinking, where this sibling does not fully understand why their parents have certain preferences or different attitudes towards their brother with DS and they tend to take these attitudes as lack of attention from his parents. It was shown that some younger siblings of people with DS perceived that their parents showed preference towards the child with this condition, finding that the possible causes cannot be easily summarized, since it is a problem of multifactorial origin. It is stated that the crisis parents go through, when the child with DS is born, must be taken into account, since it is a relevant event for the other members of the nuclear family [22].

Lizasoain, points out that children with disabilities bring enjoyment and well-being to themselves and their family's life [13]. In Van Riper, Marcia different investigations, she has stated that most of the siblings indicated that they had a positive relationship with their parents and their brother/ sister with Down syndrome. Also, they had positive or neutral feelings about the effect of having a sibling with these conditions. In addition, they had a positive perception of their own self-esteem. Most siblings are actively involved in helping the person with Down syndrome, this seemed to have a positive impact on the relationship between them [2325]. It is found that, in the present investigation, these findings coincide with the positive relationships that sibling maintains with the rest of the family nucleus, finding that almost all brothers who participated in the study feel satisfied with the family relationship that currently they have and $100 \%$ feel loved by their family, in the same way, $70 \%$ of the siblings actively participate in the activities of the sibling with DS.

In the present research, the siblings of people with DS do not have difficulties regarding the relationships they maintain with their friends, $100 \%$ of the siblings consider they manage to express themselves freely with this social group. Regarding the moment of introducing their sibling with DS to a group of friends, they were proud to introduce them. These findings differ from those found in the searching for these social needs, where it was observed that, in a study carried out by Tizard and Grad, cited by Niella [6], 75\% of the siblings of children with disabilities maintain social relationships very limited in relation to siblings of people without disabilities. The authors state that this isolation may be exacerbated by the shame that some feel when "exposing" their brother with a disability in public. Although they confirm that almost everyone overcomes this feeling.

Regarding the affective needs, some negative aspects the sibling could acquire or feel by living with a brother/ sister with DS, Skotko, et al. have also studied some negative feelings occur frequently among these individuals; they had affection for their sibling with Down syndrome; and $94 \%$ of older siblings expressed feelings of pride. Less than $10 \%$ felt ashamed and less than $5 \%$ expressed the desire to change their sibling for another brother or sister without Down syndrome [26].

In relation to these named characteristics, in the present study it was identified what negative qualities or feelings these siblings had acquired, finding that $46.6 \%$ expressed that they did not acquire this type of negative characteristics, although $20 \%$ of the siblings reported having felt fear, guilt, loneliness and doubt.

According to the results of the present investigation, siblings acquired much more gains and positive qualities than negative qualities. These characteristics were: increased perseverance, sensitivity toward others, patience, solidarity, creativity, courage, listening skills, justice and self-assurance, finding a direct relationship with the information previously mentioned, it should be noted that each brother follows a different adaptation process, although there are similar needs and strategies for solving problems, but these are not necessarily disturbed by the presence of their brother with a disability, but often the coexistence they have with him or her is positive, it directly influences them and provides them with feelings and life values that other individuals take longer to achieve.

Economic needs are variables that influence siblings because their experiences can vary according to social class. In the present investigation, $90 \%$ of the participants reported not having presented financial difficulties to solve or help their sibling with DS. This fact can be directly related to the middle stratum found by most of the siblings, as well as the level of academic training of those who are mostly in university studies. In the same way, this fact can also be related to the findings found in a study carried out by Lizasoain, which indicates that families of middle and upper social classes tend to seek help from specialists, on the contrary of lower-class families, they resort to the use of their own family resources [13]. 


\section{Coping levels in siblings of people with DS}

Regarding the coping levels shown in the present investigation by the siblings, it was found that they were at a medium level, a result obtained thanks to the use of the questionnaire on adaptation and coping by Callista Roy (EsCAPS) $[27,28]$. It is important to remember that the nursing professional needs to be based on a nursing model, based on scientific and philosophical principles which allows them to understand and interpret nursing care issues [28].

Callista Roy defines coping as a process and result by which people with thoughts and feelings, individually or in groups, use conscious awareness and choose to create human and environmental integration [29]. Knowledge of this concept allows professionals to question their attitude in practice and the application of the nursing process, integrating the individual as a holistic being. It should be considered that the person is immersed in an environment constituted by their beliefs, values, principles, feelings, experiences and relationship patterns, among others, which determine the way the individual will face environmental stimuli [29].

For this reason, the integration of this nursing theory is so important in the visualization of this research. Given that, it allows the following: a). understand that the siblings of people with DS are holistic beings, that multiple factors interact in their environment, which may depend on or modify the way they respond to situations, in this case, living with a sibling with DS. As has been seen in the different studies and previous results, there are various factors that influence the way the sibling adapts to the different needs they present. b). Recognizing the needs and coping levels of these siblings, linked to a theoretical reference such as Callista, allows improving nursing care focused on this member and not only on parents as is mostly done, as well as improving the bond between members by being recognized in a process that needs each of them for the birth or growth of a person with DS.

Finally, c). It is necessary to highlight the goal of nursing, which is to help the person, family or community, in this case the person with DS, to adapt the four modes of coping explained by Callista, which are:

Physiological function: it implies the basic needs of the organism and the forms of adaptation. In this case, this mode has no differences with respect to other subjects of care that are not siblings of people with DS [30].

Self-concept: refers to beliefs and feelings about oneself. It encompasses physical identity, personal identity, moral and ethical identity. This mode can be identified in the way the brother recognizes himself as an important entity within the family nucleus and especially for his brother [30].

Role function: It involves rational behaviors of the person's rol in the society; it depends on the way a person interacts with others in a specific situation, the nursing professional must identify what role the sibling of the person with DS has around the relationship they maintain with their family, to propose nursing care focused on these realities [30].

Interdependence: implies the relationship of the person with their relatives and the support systems where the nursing professional must recognize this brother as an integral being, who has different affective needs, family needs, social needs, economic needs, time needs, and access information needs where they interact with the environment and their own concept to achieve effective coping [30].

Within the literature review on the implementation of the instrument validated by Callista Roy applied in the present investigation, no work was found in the region where this questionnaire has been used in siblings of people with DS. However, studies related to the family members' adaptation process to a chronic disease were found [31,32]. This review made it possible to identify some stimuli that intervene in the adaptation process of people with chronic diseases and their families. This is how social support has been identified as a positive contextual stimulus for the recovery of these care subjects.

Regarding the findings in the present research, the stimuli related to the medium level of coping in siblings of people with DS, it is found that they present different resources at a family and personal level, such as: having good relations with the entire family nucleus and friends, manifestation of positive feelings towards their brother/sister and not having difficulties linked with time management or financial needs, this fact is related to variables Callista expresses regarding to the influence of these in adaptation; where, the more resources and support the person has, the better their coping will be. In the same way it can be inferred that it does not achieve a high level of coping because most of the siblings did not receive a preparation for the welcome or explanation of their sibling's situation, circumstances of interest for possible nursing care to intervene with this member of the family group.

On the other hand, regarding the studies related to adaptation in siblings of people with disabilities without the identification of a nursing theorist, these focused on comparing the siblings or families of people with some type of disability in relation to other groups that do not have a member with these qualities.

\section{Conclusion}

Recognizing the needs in siblings of people with DS is essential to understand the factors that can influence the way they respond to the situation of having a sibling with the condition. Various needs were evidenced, such as: time, emotional, family, social, economic and access to information needs. 
Highlighting these needs allows the nursing professional to identify the siblings of people with DS who have special needs that are different from the rest of the family nucleus, being aware of the negative and positive aspects that are generated, and thus establish interventions aimed at reducing negative emotions and improve the gain correlated with having a sibling with DS.

Identifying the coping levels of the siblings of people with DS, allowed to nurture the characterization of these siblings about how they respond to the fact of having a sibling with DS, together with the contextualization of a theoretical reference such as Callista Roy is in her Adaptation and Coping model, where she allowed to provide support and link with strengthening of nursing interventions in the discipline based on the application of theoretical references.

\section{Recommendations}

Within the literature review that was carried out, no studies were found on the education and integration of these siblings in nursing plans and counseling by other professionals, therefore, it is recommended to delve into these important aspects for inclusion of this member regarding the arrival or growth of their sibling with DS.

It is recommended to go further in studies where the role of the nursing professional is reflected regarding the care that can be provided to siblings of people with DS, such as: Information on causes, health complications, on breastfeeding, early stimulation, skin-to-skin contact and on management of the crisis before the birth of the child with DS.

Due to small sample size, there were limitations regarding this aspect, because a small population was chosen. It is recommended for future research to carry out studies with larger samples.

It is recommended to relate studies that inquire about current profession or academic aspirations of the participant, since findings related to the condition of having a sibling with DS and practicing a profession in a humanitarian field such as health professionals were found in the literature.

It is recommended to do more research studies conducted on siblings of people with DS with an emphasis on coping strategies and the application of the Nursing Care Process.

\section{Acknowledgement}

We acknowledge the postgraduate management and the research coordination of the Faculty of Nursing and Rehabilitation at Universidad de la Sabana for the authorization and use of the EsCAPS coping and adaptation process measurement scale in Spanish.

\section{References}

1. Organizaciòn Mundial de la Salud. Anomalias congénitas 2014.
Disponible en: Desde. 2014. http://www.who.int/mediacentre/ factsheets/fs370/es/

2. de Graaf G, Buckley F, Skotko B. Estimates of the live births, natural losses, and elective terminations with Down syndrome in the United States. Am J Med Genet A. 2015; 167A: 756-767. PubMed: https://pubmed.ncbi.nlm.nih.gov/25822844/

3. Bull MJ. Down Syndrome. N Engl J Med. 2020; 382: 2344-2352. PubMed: https://pubmed.ncbi.nlm.nih.gov/32521135/

4. De Graaf G, Buckley F, Skotko B. Estimation of the number of people with Down syndrome in Europe. Eur J Hum Genet. 2020; 29: 402-410.

5. Departamento Administrativo nacional de Estadística. Censo Colombia 2005 [Internet]. DANE; 2005. Disponible en: https://www.dane.gov. co/index.php/estadisticas-por-tema/demografia-y-poblacion/censogeneral-2005-1

6. Bull M. Down Syndrome. N Engl J Med. 2020; 382: 2344-52. PubMed: https://pubmed.ncbi.nlm.nih.gov/32521135/

7. Kreicher K, Weir F, Nguyen S, Meyer T. Characteristics and progression of hearing loss in children with Down syndrome. J Pediatr. 2018; 193: 27-33.

PubMed: https://pubmed.ncbi.nlm.nih.gov/29174076/

8. Bull MJ. Improvement of outcomes for children with Down syndrome. J Pediatr. 2018; 9-10.

PubMed: https://pubmed.ncbi.nlm.nih.gov/29212622/

9. Gadsboll K, Petersen O, Gatinois V, Strange H, Jacobsson B, et al. Current use of noninvasive prenatal testing in Europe, Australia and the USA: a graphical presentation. Acta Obstet Gynecol Scand. 2020; 99: 722-730.

PubMed: https://pubmed.ncbi.nlm.nih.gov/32176318/

10. Stoneman Z. Examining the Down syndrome advantage: mothers and fathers of young children with disabilities. J Int Disabil Res. 2007; 51 : 1006-1017.

PubMed: https://pubmed.ncbi.nlm.nih.gov/17991008/

11. Skelton B, Knafl K, Van Riper M, Fleming L, Swallow L. Care Coordination Needs of Families of Children with Down Syndrome: A Scoping Review to Inform Development of Health Applications for Families. Children. 2021; 8: 558.

PubMed: https://pubmed.ncbi.nlm.nih.gov/34209506/

12. Phelps R, Lollar D, Medlen J, Bethell C. Health care needs of children with Down syndrome and impact of health system performance on children and their families. J Dev Behav Pediatr. 2012; 3: 214-220. PubMed: https://pubmed.ncbi.nlm.nih.gov/22249385/

13. Lizasoáin O. Discapacidad y familia: el papel de los hermanos. En: El largo camino hacia una educación inclusiva. España: Universidad Pública de Navarra; 2009; 125.

14. Gashmard R, Ahmadi F, Kermanshahi SMK. Coping strategies adopted by Iranian families of children with Down syndrome: A qualitative study. Medicine. 2020; 99: e20753.

PubMed: https://pubmed.ncbi.nlm.nih.gov/32664068/

15. Cuskelly M. Contributors to Adult Sibling Relationships and Intention to Care of Siblings of Individuals With Down Syndrome. Am J Intellect Develop Disabilities. 2016; 121: 204-218.

PubMed: https://pubmed.ncbi.nlm.nih.gov/27119212/

16. Down España. Familias y síndrome de Down: Apoyos y marcos de colaboración. Gobierno de España; Disponible en.2012. https://www. sindromedown.net/wp-content/uploads/2014/09/146L_14.pdf

17. Pourbagheri N, Akbarzadehbaghban A, Mirzakhani N. Comparison of Emotional-Behavioral Problems of Siblings at the Age Range of 3-9-Year-Old Children with Autism and Down Syndrome. Iran J Child Neurol. 2018; 12: 73-82.

PubMed: https://pubmed.ncbi.nlm.nih.gov/29696048/

18. Roberts R, Ejova A, Giallo R, Strohm K, Lillie M. Support group programme for siblings of children with special needs: predictors of 
improved emotional and behavioural functioning. Disabil Rehabil. 2016; 38: 2063-2072.

PubMed: https://pubmed.ncbi.nIm.nih.gov/26728633/

19. Caliendo M, Lanzara V, Vetri L, Rocella M, Marotta R, Carotenuto M, et al. Emotional-Behavioral Disorders in Healthy Siblings of Children with Neurodevelopmental Disorders. Kaunas. 2020; 56: 491.

PubMed: https://pubmed.ncbi.nlm.nih.gov/32977671/

20. España D. Guía de autocuidado emocional para hermanos de personas con síndrome de Down [Internet]. Down España. Disponible en. 2017. https://www.sindromedown.net/wp-content/uploads/2015/09/ Autocuidado-emocional-para-hermanos-de-personas-con-s--ndromede-Down-2017.pdf

21. Skotko B, Levine $S$. What the other children are thinking: brothers and sisters of persons with Down syndrome. Am J Med Genet C Semin Med Genet. 2006; 142: 180-186.

PubMed: https://pubmed.ncbi.nlm.nih.gov/16823778/

22. Hastings R, Petalas M. Self-reported behaviour problems and sibling relationship quality by siblings of children with autism spectrum disorder. Child Care Health Dev. 2014; 40: 833-839.

PubMed: https://pubmed.ncbi.nlm.nih.gov/24460897/

23. Choi H, Van Riper M. Adaptation in families of children with Down syndrome in East Asian countries: an integrative review. J Adv Nurs. 2017; 73: 1792-1806.

PubMed: https://pubmed.ncbi.nlm.nih.gov/27987318/

24. Lee A, Knafl K, Van Riper M. Family Variables and Quality of Life in Children with Down Syndrome: A Scoping Review. Int J Environ Res Public Health. 2021; 7: 419.

PubMed: https://pubmed.ncbi.nlm.nih.gov/33430335/
25. Van Riper M, Knafl G, Figueiredo M, Caples M, Choi H, et al. Measurement of Family Management in Families of Individuals with Down Syndrome: A Cross-Cultural Investigation. 2021; 27: 8-22. PubMed: https://pubmed.ncbi.nlm.nih.gov/33272069/

26. Skotko BG, Levine SP, Goldstein R. Having a brother or sister with Down syndrome: Perspectives from siblings. Am J Med Genet. 2011; 155: 2348-2359.

PubMed: https://pubmed.ncbi.nlm.nih.gov/21910244/

27. Hernández J, Jaimes $M$, Carvajal J, Suárez D, Medina $P$, et al. Modelo de adaptación de Callista Roy: instrumentos de valoración reportados por la literatura en escenarios cardiovasculares. Cultura de cuidado de enfermería. 2016; 13: 6-21.

28. Moreno M. Importancia de los modelos conceptuales y teorías de enfermería: experiencia de la Facultad de Enfermería de la Universidad de La Sabana. Revista Aquichan. 2005; 5: 44-55.

29. Díaz L, Durán M, Gallego P, Gómez B, Gómez E, González Y, et al. Análisis de los conceptos del modelo de adaptación de Callista Roy. 2002; 2: 19-23.

30. Russo S, Baumann S, Velasco-Whetsell M, Roy C. A Comparison of Two Case Studies Using the Roy Adaptation Model: Parents of OpioidDependent Adults and Bariatric Surgery. Nurs Sci Q. 2019; 32: 61-67. PubMed: https://pubmed.ncbi.nlm.nih.gov/30798751/

31. Rojas Y, Montalvo A, Díaz A. Afrontamiento y adaptación de cuidadores familiares de pacientes sometidos a procedimientos cardioinvasivos. Univ Salud. 2018; 20: 131-138.

32. Osorio E, Lopeira P, Acosta D. Cuidado al familiar del paciente críticamente enfermo desde la teoría de Callista Roy. Duazary. 2019; 16: $50-62$. 